\title{
O USO DA METODOLOGIA WEBQUEST NO ENSINO DE LÍNGUA INGLESA NO CURSO DE SECRETARIADO EXECUTIVO TRILÍNGUE: UM RELATO DE EXPERIÊNCIA
}

\author{
The Use of the Webquest Methodology in English Language Teaching in an Office \\ Management Undergraduate Course: an Experience Report ${ }^{1}$
}

\author{
Adriana Cristina Sambugaro de Mattos BRAHIM, Centro Universitário \\ Internacional UNINTER ${ }^{2}$ \\ Iara Maria BRUZ, Centro Universitário Internacional UNINTER ${ }^{3}$ \\ Edna Marta Oliveira da SILVA, Centro Universitário Internacional UNINTER ${ }^{4}$
}

\begin{abstract}
RESUMO: Desde o advento da internet em nosso cotidiano, muito tem sido discutido a respeito da sua aplicabilidade como um facilitador dos processos de ensino e aprendizagem. Uma vez que é função do educador preparar o discente para o mundo globalizado em que vivemos, os professores não podem fechar os olhos à realidade ao seu redor e ignorar a influência que a internet tem em nosso cotidiano. Baseado nessa observação e no fato de que a construção do conhecimento se dá na relação com o outro, pode-se perguntar se é possível pensar em uma nova metodologia que dê conta de aliar o avanço tecnológico e a convivência em grupo. Assim, foi desenvolvida a metodologia Webquest que tem por princípio usar os recursos disponíveis na internet com atividades colaborativas. O objetivo deste trabalho é relatar uma experiência com o uso de tecnologia no ensino de língua inglesa tendo como base a metodologia Webquest como recurso didático e elemento facilitador para aquisição de língua. A experiência contou com a participação de alunos de um curso de graduação de Secretariado Executivo Trilíngue de uma instituição de ensino superior.
\end{abstract}

PALAVRAS-CHAVE: Internet; Webquest; Ensino de Língua Inglesa.

\begin{abstract}
Since the advent of the internet in our daily life, its applicability as a facilitator of the teaching and learning processes has been intensively discussed. Once the teacher's educational role is to prepare learners for the globalized world in which we live in, the teachers cannot close their eyes to the reality around them and ignore the influence that the internet has on one's life. Based on this observation and on the fact that knowledge construction occurs when relating one to another, it can be asked whether it is possible to think of a new methodology that may cope with the technological advances and group interaction at the same time. Thus, the Webquest methodology was developed by using available resources on the internet, and collaborative work. The goal of this paper is to
\end{abstract}

\footnotetext{
${ }^{1}$ A fundamentação teórica aqui apresentada é parte de um trabalho já desenvolvido por uma das autoras deste relato de pesquisa.

${ }^{2}$ Doutora em Linguística Aplicada pela UNICAMP (2008). É especialista em Formação de Docentes e de Orientadores Acadêmicos (tutores) em Educação a Distância (2012) pelo UNINTER.

${ }^{3}$ Mestre em Educação pela Universidade Federal do Paraná (2012).

${ }^{4}$ Especialista em Ensino de Línguas Estrangeiras Modernas pela Universidade Tecnológica Federal do Paraná (2008).
} 
report an experience with the use of technology in English teaching based on the Webquest methodology as a didactic resource and facilitator for language acquisition. The experience counted on the students' participation from an Office Management undergraduate course from a higher education institution.

KEY-WORDS: Internet; Webquest; English Language Teaching.

\section{INTRODUÇÃO}

É facilmente observável que a sociedade em que vivemos é muito visual. Nesse aspecto, a internet é uma das mídias da atualidade capaz de aliar diferentes recursos visuais que vão além do simples texto escrito associado a imagens. É fato que a internet atrai populações de diferentes faixas etárias a se aventurarem não somente nas múltiplas formas de interação que proporciona, mas também como ferramenta de aquisição de informação e de conhecimento. Tal peculiaridade agrega à internet um potencial de uso como uma ferramenta pedagógica muito promissora nas diversas áreas do conhecimento, incluindo o ensino de línguas estrangeiras.

Neste contexto de ensino, dois aspectos em relação à internet reforçam a ideia de seu uso com objetivos pedagógicos. Em primeiro lugar, aumenta a possibilidade de estar em contato com a língua alvo em outros momentos, fora da sala de aula. Além disso, uma das únicas referências linguísticas para os alunos durante as aulas acaba sendo somente o(a) professor(a) e o material didático utilizado. Em contrapartida, a navegação por sites na internet permite o contato direto com pessoas que utilizam a língua alvo nos mais diversos contextos. Isso sem mencionar o acesso às diferentes fontes de informação que podem ser atualizadas em tempo real ou não. Em outras palavras, o(a) aluno(a) pode ser exposto à língua estrangeira a qualquer hora e em qualquer lugar onde haja um computador com acesso à rede. Assim, conforme afirma Braga (2013, p. 51):

(...) atualmente as redes sociais e as publicações on-line propiciam diferentes oportunidades para a exposição e uso da língua alvo. Pode-se mesmo dizer que aprendizes de línguas estrangeiras, mesmo sem sair de seu próprio espaço geográfico, têm a possibilidade de usufruir uma "imersão linguística virtual" que permite o acesso a situações reais de uso da língua. $\mathrm{O}$ fato de a maioria dessas interações ocorrerem através da escrita não é problema e sim uma vantagem para aprendizes. Fora das situações de comunicação on-line (como aquelas que ocorrem nas salas de bate-papo), os alunos podem produzir, rever e mesmo corrigir seus enunciados antes de postá-los. 
Por outro lado, ao mesmo tempo em que a internet traz uma gama infinita de formas de comunicação e interação, é igualmente fácil para o seu usuário perder seu "rumo" durante a navegação. Porém, como afirma Braga (2013, p. 57) "navegar é preciso" e, "independentemente da avaliação sobre as vantagens e desvantagens que esses novos recursos trazem, é fato que eles já estão implantados nas práticas sociais”. Então, é tarefa dos professores planejar o uso de recursos disponibilizados na rede para que sejam explorados de forma individual e socialmente construtiva. Além disso, diante deste contexto, conforme Rojo (2013), é necessário que os professores tenham um olhar em relação aos desafios que os multiletramentos e os textos contemporâneos trazem para a educação de línguas, especialmente e, neste caso, o letramento digital pois, segundo nos informa a autora, isso implica negociar uma crescente variedade de linguagens e discursos: interagir com outras línguas e linguagens, interpretando ou traduzindo, usando interlínguas específicas de certos contextos, usando inglês como língua franca; criando sentido da multidão de dialetos, acentos, discursos, estilos e registros presentes na vida cotidiana, no mais pleno plurilinguismo bakhtiniano. Ao invés da gramática como norma para a língua padrão, uma gramática contrastiva que, como Ártemis, permite atravessar fronteiras.

Como, então, organizar toda a oferta possível da internet de modo que se possa obter algum resultado efetivo para aquisição de uma língua estrangeira? Para responder a essa pergunta, a metodologia Webquest, criada em 1995, pelo professor Bernie Dodge, da Universidade de San Diego, pode ser uma proposta bastante atrativa.

Segundo Dodge (1995), a Webquest é "uma atividade investigativa, em que alguma ou toda a informação com que os alunos interagem provém da Internet." (SENACSP, 2003). Além disso, há também a promoção do trabalho colaborativo. Para o mesmo autor, "as Webquests estão fundadas na convicção de que aprendemos mais e melhor com os outros, não individualmente. Aprendizagens mais significativas são resultados de atos de cooperação" (1995 apud Rocha, 2007, p. 60). Essa ideia também vai ao encontro dos estudos desenvolvidos por Vygotsky (2007) em relação à interação social em processos de aprendizagem. Segundo esse autor, “o aprendizado humano pressupõe uma natureza social específica" (Ibid., p. 100). Nesse sentido, a aprendizagem cooperativa é um item indissociável da Webquest.

Outra característica da Webquest, na perspectiva de Rocha (2007), é a sua adaptabilidade, pois pode não só ser utilizada não somente nas mais diversas áreas do conhecimento humano, mas também com aprendizes das mais diferentes idades e com 
qualquer nível de aprendizado.

\section{DESENVOLVIMENTO}

Após as considerações a respeito da Webquest, pensamos na possibilidade de incluí-la como ferramenta de avaliação de produção oral em língua inglesa. O curso de Secretariado Executivo Trilíngue, no qual ministramos aulas de inglês, possui seis semestres de duração e, durante todos os semestres, os alunos têm o inglês em sua grade curricular. São 80 horas por semestre, totalizando 480 horas ao final do curso. Entretanto, a carga horária ofertada pela instituição não é suficiente para proporcionar aos alunos um nível intermediário de competência linguístico-comunicativa ao final do curso. Este fato gera comentários entre os alunos e, da mesma forma, insatisfação não só para eles, mas também para os professores.

$\mathrm{Na}$ tentativa de procurarmos alternativas para o problema, sugerimos a utilização do Ambiente Virtual de Aprendizagem (AVA), ferramenta usada ara os cursos da modalidade a distância da mesma IES, aumentando a carga horária de estudo de inglês, semanalmente. ${ }^{5}$ Portanto, usar recursos da internet em nossas aulas é uma prática iniciada no primeiro semestre de 2012. Como os alunos têm acesso ao AVA, oferecido pela instituição, disponibilizamos nesse ambiente um link de acesso para uma Webquest organizada pelas autoras deste trabalho. Foram incluídas algumas explicações em português e a Webquest toda em inglês. A partir da adaptação de um projeto de autoria de Denise Roselan (2003), professora americana de Wisconsin sobre como organizar uma viagem de negócios, elaboramos uma Webquest com o auxílio do site Zunal. Este site fornece um passo-a-passo de como criar e publicar uma única Webquest gratuitamente (para mais de uma Webquest é necessário pagar uma taxa de acesso ao site). Além da página inicial Bem-vindo ${ }^{6}$ (figura 1), a Webquest também contava com outras páginas: Introdução, Tarefa, Processo, Avaliação e Conclusão ${ }^{7}$, cada qual com detalhes específicos a serem observados e orientações que os alunos deveriam seguir.

\footnotetext{
${ }^{5}$ Apenas a título de informação, esta alternativa é parte de um projeto que está em andamento e em fase de coleta de dados. Se a hipótese de que o uso do AVA, como ferramenta para proporcionar um aumento de carga horária de estudo semanal de inglês, melhora o nível de competência linguístico-comunicativa, o projeto será ampliado para os outros idiomas estudados no curso de Secretariado Executivo Trilingue.

${ }^{6}$ Welcome (Todas as traduções neste trabalho são de responsabilidade das autoras)

${ }^{7}$ Introduction, Task, Process, Evaluation, and Conclusion, respectivamente.
} 


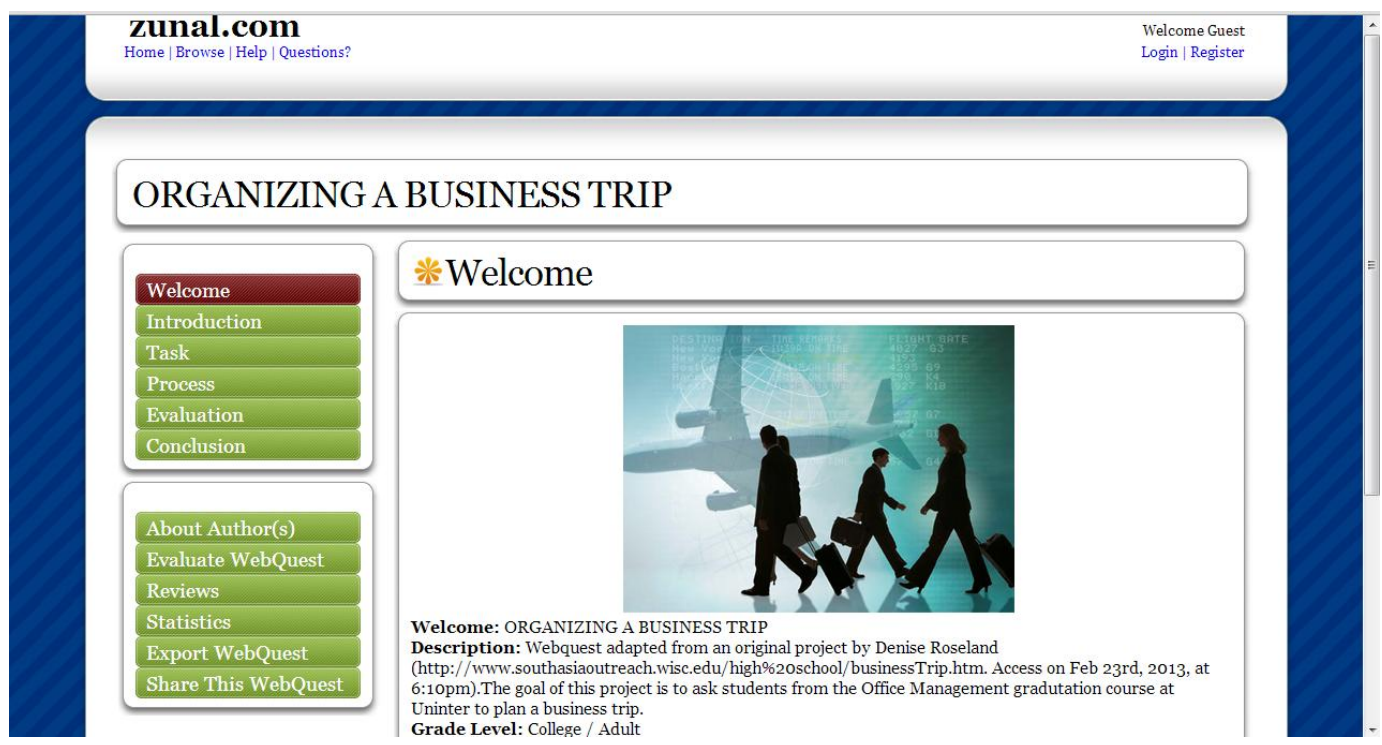

Figura 1: tela inicial da Webquest realizada com os alunos.

Em Introdução, contextualizamos uma situação. Os alunos, colocando-se como secretários executivos de uma empresa, deveriam organizar uma viagem de negócio para o presidente e seus diretores. Nessa página, constavam a data da viagem, o local (Amsterdam, Holanda) e o motivo da viagem (para participarem de uma feira tecnológica). Em Tarefa, foram apresentadas as metas a serem cumpridas. Por se tratar da organização de uma viagem de negócios, os alunos deveriam reunir todas as informações necessárias a respeito do país de destino (clima, fuso horário, moeda, idioma oficial, informações sobre alimentação, cultura, locais a serem visitados, além de algumas expressões básicas do idioma do país (tais como cumprimentos e agradecimentos), fazer reservas de hotel, passagens e meios de transporte, necessidade de visto de entrada e passaporte. Os alunos também deveriam incluir uma previsão de custos de viagem.

Com todas as informações em mãos, foi sugerido que o plano de viagem fosse apresentado em PowerPoint em data previamente agendada. Em Processo, foram disponibilizados links de sites para orientar a pesquisa dos alunos. Cabia, então, aos alunos, organizar as informações e montarem suas apresentações. Também nesse item foram dadas instruções a respeito da formação dos grupos (pares ou trios), forma de apresentação (em PowerPoint) e da importância em ensaiar a apresentação para evitar a leitura. Em Avaliação, foram disponibilizados os critérios para a avaliação das apresentações por partes das professoras, adaptados de dois sites: da professora Carolina LaMagna e do 
ECCE Speaking Score Levels. ${ }^{8}$ Finalmente, em Conclusão, é apresentado o objetivo final do trabalho, que foi o de simular uma situação real em sua área de atuação, além dos créditos e referências utilizadas para a construção da Webquest.

A Webquest foi aplicada em um grupo de 36 alunos do $3^{\circ}$ período do curso de Secretariado Executivo Trilíngue, separados em duas turmas. Os alunos, a princípio, questionaram a quantidade de tarefas a serem executadas. Por ter sido a primeira experiência com a metodologia, era de se esperar que os alunos se sentissem inseguros em um primeiro momento. Entretanto, após ter sido explicada cada uma das etapas da Webquest e quais tarefas teriam que ser executadas, os alunos perceberam que vários tópicos estavam diretamente relacionados àqueles estudados não somente no semestre atual, mas também nos dois anteriores (como, por exemplo, vestuário, clima, viagens, hora, meios de transporte, comida, números e preços). Superada a ansiedade inicial, foi nítido o envolvimento dos alunos com o trabalho. Alguns dos alunos que já atuam como secretários executivos afirmaram ter vivenciado algo muito semelhante a suas práticas profissionais. A diferença, no caso da Webquest, é que as tarefas teriam que ser realizadas em inglês.

O prazo para a realização das tarefas da Webquest foi de 30 dias. No dia agendado, as apresentações dos trabalhos foram feitas para os demais colegas e para as professoras da disciplina. Todos os grupos utilizaram recursos visuais com apresentações em PowerPoint e em vídeos. A maior parte dos alunos cumpriu todas as tarefas propostas na Webquest. Somente um grupo não incluiu a previsão de orçamento da viagem. Entretanto, pode ser observado, de forma geral, que o foco dos trabalhos foi mais na questão turística do que em uma viagem de negócios propriamente dita. Na questão linguística, um fato que chamou a atenção foi o da inclusão de estruturas gramaticais ainda não apresentadas em aula, mas que foram utilizadas corretamente pelos grupos. O mesmo ocorreu com o uso de vocabulário.

Ao final das apresentações, os alunos foram unânimes em relação ao trabalho proposto com o uso da Webquest: a) apesar de ter sido uma atividade que exigiu muita preparação e pesquisa, eles puderam aproximar a teoria com o uso prático do idioma; b) contextualizou a prática profissional; c) ampliou o conhecimento de mundo em relação aos aspectos culturais do país escolhido (Holanda). Quando perguntados sobre a possibilidade

\footnotetext{
${ }^{8}$ Disponível em:

<http://www.cambridgemichigan.org/sites/default/files/resources/ECCE_2013_SampleTest/ECCE_2013_Sa mpleTestGuide.pdf>
} 
em se implantar a metodologia Webquest como forma de avaliação da oralidade, todos foram muito receptivos à ideia.

\section{CONSIDERAÇÕES FINAIS}

Se o objetivo de um curso de formação profissional tal como é o curso de Secretariado Executivo Trilíngue é o de formar profissionais capacitados em se comunicar em duas línguas estrangeiras - sendo uma delas, a língua inglesa - a metodologia Webquest apresenta-se como uma possibilidade real para seu uso como recurso didático, pois não somente aproxima o (a) aluno (a) da sua prática profissional, mas também contextualiza o seu aprendizado, tornando-o significativo. Isso, sem dúvida alguma, foi um fator de motivação dos alunos para o cumprimento das tarefas propostas. Há, portanto, de se pensar em propôr o uso dessa metodologia na prática pedagógica dos professores de idiomas da instituição.

\section{REFERÊNCIAS}

BRAGA, D. B. Ambientes Digitais - reflexões teóricas e práticas. São Paulo: Cortez, 2013.

CaMLA Cambridge Michigan Language Assessments. ECCE - Examination for the Certificate of Competency in English. Disponível em:

<http://www.cambridgemichigan.org/sites/default/files/resources/ECCE_2013_SampleTest /ECCE_2013_SampleTestGuide.pdf> Acesso em 11 jul. 2013.

DODGE, B. WebQuests. Disponível em: < http://webquest.org/> Acesso em: 11 jul. 2013. LAMAGNA, C. Virtual classroom. Disponível em: < http://eclassroom.110mb.com/ WebQuestRubric.pdf> Acesso em 11 jul. 2013.

ROCHA, L. R.. A Concepção de Pesquisa no Cotidiano escolar: Possibilidades de Utilização da Metodologia Webquest na Educação pela Pesquisa. 2007. 200f. Dissertação (Mestrado em Educação). Setor de Educação. Programa de Pós-Graduação em Educação. Universidade Federal do Paraná, Curitiba, 2007.

ROJO, R. (org.). Escola Conectada - os multiletramentos e as TICs. São Paulo: Parábola, 2013.

ROSELAND, D. Organizing a Business Trip: A Technology-Integrated Project. Disponível em: < http://www.southasiaoutreach.wisc.edu/high\%20school/businessTrip. htm> Acesso em: 11 jul. 2013.

SENAC-SP. Webquest: O Que É. São Paulo, 2003. Disponível em: <http:// http://webquest.sp.senac.br/textos/oque > Acesso em: 13 out. 2007

ZUNAL. Zunal Webquest Maker. Disponível em: < http://zunal.com/index.php> Acesso em 11 jul. 2013.

VYGOTSKY, L. S. A Formação Social da Mente. $7^{\text {a }}$ Edição. São Paulo: Martins Fontes, 2007. 